\title{
The line between 'knowing' and 'doing': medicine's dilemma at the end of the twentieth century
}

\author{
William A Silverman
}

Science teaches us to doubt, and, in ignorance, to refrain

Claude Bernard

As can be seen from the title of this essay, I want to make a distinction between the realm of 'knowing' and that of 'doing' in medicine. The application of knowledge or expertise, it can be argued, is analytically distinct from the acquisition and possession of that knowledge or expertise.

Freidson pointed out a difference between the occupations labelled the 'consulting' professions, as opposed to kinds of work classified as 'scholarly', 'learned', or 'scientific'. 1

\section{CONSULTING PROFESSIONS}

The consulting trades are expected to solve practical problems brought to them by ordinary people. The consultants can survive only if they can earn the confidence of a demanding clientele. Practitioners must provide services that are generally perceived to be effective solutions to practical difficulties.

\section{LEARNED PROFESSIONS}

The scholarly professions, on the other hand, are expected to be the elaborators of theory and the repositories of imputed knowledge. In order to prosper, Freidson emphasises, scholars need gain only the interest and patronage of a powerful sponsor. There is no need to win the confidence of the public at large.

\section{MEDICAL PROFESSION} occupation are assigned to one general class; but the conditions for the establishment and the maintenance of the two subclasses are, in fact, quite different. They need to be examined separately.

The Cochrane Centre, Oxford

Correspondence to: Professor W A Silverman, $90 \mathrm{La}$ Cuesta Drive, Greenbrae, California 94904, USA.

For example, medicine first attained the status of a learned profession in the Middle Ages. Recognition followed the rise of the university in Europe, and the increased importance of learning as perceived by the

\section{Types of professions}

In the profession of medicine, the two types of

elite. The university trained doctors gained the support of the state, which granted them the authority to be the sole arbiters of medical work.

But medicine did not become a consulting profession, to any important extent, until the work itself became attractive to the public. Widespread acknowledgment took place less than 150 years ago - it followed the construction of an increasingly solid scientific foundation (particularly after acceptance of the germ theory of disease). Only then did the work of medicine begin to be widely seen as superior to the ministrations of a colourful variety of self proclaimed healers. Before these relatively recent developments, university trained physicians were unable to claim a monopoly over the work of healing. The certified doctors were unable to attract widespread public confidence.

The distinction between scholar and practitioner was, and is, still seen most clearly at the bedside. When problems are brought to them, frontline doctors behave like engineers. In both of these consulting professions, practitioners are obliged to act on the basis of incomplete knowledge. These pragmatists simply have to manage with as much truth as is currently available to them - action in the applied sciences is always an informed compromise. And we must admit that as compared with our small pond of knowledge in medicine, our ignorance is Atlantic.

\section{Therapeutic imperative}

The assumption by the public that a doctor is competent creates a pragmatic compulsion for action; and it is the act that certifies a doctor's worth in the eyes of patients and their families. ${ }^{2}$ Effective action is, of course, highly desirable, but even when interventions have very little chance of success, they are much preferred over watchful waiting. This action oriented stance has been labelled an 'optimistic bias'. ${ }^{3}$ It turns up in all kinds of situations in everyday life, particularly where there is substantial uncertainty, and where there is strong emotional interest in the force of action.

'Do something, anything!' is a universal cry illness. Throughout all of human history, 'healers' have responded with imagination and boundless enthusiasm. 
SISTER KENNY'S HOT PACKS

I first saw an instructive example of the 'therapeutic imperative' in New York City during a poliomyelitis epidemic in the late summer of 1944, 50 years ago. I was a resident at The Babies Hospital of Columbia University when the outbreak occurred. It quickly became the largest epidemic in the city's history, and an entire floor of the hospital was set aside for polio patients.

In a back ward, we had four cumbersome Drinker respirators (the so-called 'iron lung' machines), and they were fully occupied for almost six weeks by a succession of patients with bulbar involvement, the highly lethal form of the disease.

The weather that summer was brutally hot and humid. In those days, hospitals were not air conditioned: the wards were like steam baths. Ambient conditions on the polio ward were made even more uncomfortable by huge copper vats of water, boiling day and night to keep the Kenny packs steaming hot. These packs, made of woollen cloth, were wrapped around the affected limbs of patients according to a regimen set out by Sister Kenny, an Australian nurse. The continuous applications of hot, moist packs were meant to relieve the immediate pain of muscular spasm; and, more importantly, it was believed they would reduce the amount of residual paralysis.

On the night I remember best, during that harrowing summer, the ward nurses, wearing masks and floor length isolation gowns, reminded me of a painting of Florence Nightingale's dedicated angels of mercy on a hospital ward during the Crimean War. They seemed to be suspended a few inches above the floor in the darkened wards, as they glided silently in a continuous shuttle between the steaming cauldrons and the naked patients lying in the ward beds. A little after midnight two patients, in Drinker respirators, died in quick succession. We were physically and emotionally exhausted.

\section{A SURREAL TUTORIAL}

About $3 \mathrm{am}$, to our amazement, the attending consultant arrived on the floor, and asked to be taken on a complete ward round. He was very drunk. His gait was unsteady and his necktie, knotted perfectly, was turned 180 degrees and hung down the back of his shirt. But he was quite sedate, his speech was not slurred, and he was completely lucid.

After we reported the details of the two deaths, we walked from bed to bed with flashlights, and he made whispered comments about each patient. He kept to a consistent theme: over and over again, he pointed out the extreme variation in the extent of paralysis among the affected children. Treatment with Kenny packs did seem to relieve the pain, he conceded, but it was impossible to know if, or indeed, how much decrease in paralysis could be attributed to treatment in this notoriously unpredictable disorder. It was well known, he reminded us, that more than half of young children with acute poliomyelitis were left with no residual motor deficit. Given the extreme variability, he asked, 'Would we even recognize a small increase in paralysis among the Kenny pack treated children?'

As I look back, a half century ago, to this bizarre, middle of the night ward round led by my drunken, but very canny teacher, I recognise this as a peak experience in my medical education. But it did take years to realise that his question about the safety, as well as the efficacy of Kenny pack treatment made a crucially important point: therapy must always be seen as a sword with at least two edges. His concern for the well being of our patients was much more responsible than our emotional preoccupation, which was driven by the fear of not doing enough! 'How can we, in good conscience, withhold packs from half of our patients', we thought to ourselves, 'if there is even the slightest hope for improvement in outlook?' It was this last fear filled question that stood in the way of finding out whether Kenny packs were helping or, in fact, harming our patients. At the time, I was indignant. How could this drunken sceptic be so cruel as to question our heroic efforts to help these children? No other treatment was available! I thought it was malicious to point out the remote possibility that a measure so simple and so seemingly benign as the hot packs might worsen outlook.

\section{GALENIC REASONING}

The nurses and the families were completely convinced the packs were working miracles: all improvement was the result of the Kenny treatment, all failures were explained away by the claim that treatment was not started soon enough.

During this very same period, it was this uncritical faith in another untested treatment that was responsible for the 12 year delay in recognising the horrendous result of an apparently simple act: turning up the flow of oxygen - a long trusted, life giving gas into the incubators for prematurely born infants. Only after the oxygen/blindness disaster ${ }^{4}$ did we recognise that the soft headed reasoning about cause and effect in medicine had changed very little over a period of two millennia.

In ancient Rome, Galen made a sweeping claim about his infallible treatment; it had a familiar ring. He said, 'All who drink of this treatment recover in a short time, except those whom it does not help, who all die. It is obvious, therefore, that it fails only in incurable cases'.

\section{The era of optimism}

Soon after the polio experience, the powerful antibiotic drugs and the corticosteroids arrived on the scene: they ushered in an unprecedented period of optimism. As I take a long look back at this era, I think it demonstrated what might be called 'the opiate effect of success'. The parade of spectacular results, after use of the new miracle drugs, led 
to a Galen-like dogmatic slumber. Success after success led to a weakening of a spirit of doubt of the kind my tipsy consultant tried so hard to encourage on that bizarre night on the polio ward.

The slam-bang effects of the new agents in the first decade or two after World War II, led to an exuberant 'let's try it and see' attitude. At every opportunity, I have spoken and written about the unbridled therapeutic sprees and unexpected treatment disasters during this uncritical period, particularly the debacles involving highly vulnerable prematurely born neonates. I will resist the compulsion to recite the gloomy story again, and mention only three lessons learned during the fitful start-up period in the history of neonatology. They are, I suggest, relevant to all of medicine. First, nothing improves the effectiveness of a new treatment like the lack of controls. Second, it is very dangerous to use treatments widely before they are subjected to rigorous comparative tests. And, finally, the hedging strategy of randomised clinical trials is a safety measure this conservative format guarantees that the number of patients injured in unexpected therapeutic disasters will be relatively small.

The lessons have, for the most part, been learned. There is no question that the explosive increase in medical knowledge in the past several decades has led to the development of safe and increasingly effective interventions. The expected time course and outcome of a growing number of human afflictions can be modified as never before in the history of our species.

\section{A new stage of medical history}

There is a rumbling note of uneasiness that underlies present day medical progress: the more we know in medicine, the more questions we encounter about what to do with the hard won information. One critic has pointed out that 'medicine has entered a new stage of its history; one where the successes, and not the failures, are the main source of our problems'. And these 'failures of success' are seen, in caricature, at both extremes of the life span. ${ }^{6}$

\section{DUBIOUS SUCCESS}

I can recall an early victory in the $1960 \mathrm{~s},{ }^{4}$ when neonatal intensive care was just getting organised in the US. A dedicated team of nurses and paediatricians (they were not yet called neonatologists) was successful in 'saving' an 800 gram infant who developed one life threatening complication after another. Three months and several tens of thousands of dollars after birth, the baby was sent home to a cold water flat in a rundown section of the city. Within a week, we heard that the infant died when a rat chewed off its nose.

\section{LIMITS OF BENEVOLENCE}

Looking back at our well intentioned, never say die fight to keep this marginally viable infant alive, I cannot in good conscience, label the struggle as an act of pure benevolence. I am forced to ask, 'Was my benevolence simply a form of self-gratification? Did I have a genuine impulse to do good, or merely a compulsion to feel good?'

One of the nurses in the special care unit described the situation faced by all young caretakers with a 'rescue fantasy'. She said, 'When I come home, dead tired, after working very hard to keep these small infants alive, I have a hard time falling asleep; I keep asking myself, "Am I doing it for the baby, or am I doing it for myself?"”

These disturbing questions are an indication of increasing unease about all acts of altruism in modern highly developed countries. One legal scholar stated the case in forceful terms, ${ }^{7}$ 'Of all tyrannies, a tyranny sincerely exercised for the good of its victims may be the most oppressive ... [T] hose who torment us for our own good will torment us without end, for they do so with the approval of their own conscience'.

A small group of humanists met a few years ago to discuss some general questions about social policy. ${ }^{8}$ They soon found themselves talking about a society's responsibility for the care of its dependants. They quickly recognised that a virtuous claim to be acting benevolently in these situations was becoming increasingly suspect. 'If the last refuge of the scoundrel was once patriotism', an observer noted, 'now it appeared to be the activity of "doing good" for others ...' (that is to say, acting in what he/she defines as the best interest of someone else).

The value of the paternalistic model in social work and in medicine needs to be questioned. 'Where', it was asked, 'should the authority of the care-giver leave off, and the rights of the cared-for begin?' For better or worse, it was observed, 'social thought and social policy in our society seems to be in the process of making a startling break with some very old and hallowed ideas'.

A judge, who heard that the topic of 'benevolence' had been discussed at the conference, criticised the group for even considering that the idea 'was anything more than the exercise of power in disguise'. C S Lewis was blunt in his opinion about all engineering efforts, and, I suspect, he would include medicine's benevolent actions. $\mathrm{He}$ said, 'Man's power over nature is really the power of some men over other men, with nature as their instrument'.

These words are quite harsh, but the criticism serves a useful purpose if it forces us to examine some long accepted notions about the work of medicine in its role as a consulting profession. For example, we need to determine the extent to which neonatal intensive care is directly responsive to problems brought to it by families. Are these highly skilled specialists responding to needs, or are they creating needs to which they respond? We need to know, I suggest, whether neonatal medicine's enormous increase in technical power has allowed it to become coercive.

It is a mistake to suppose that any technical 
innovation has one, and only one, effect. 'Every technical development is both a blessing and a burden', said one social critic': 'not either-or, but this-and-that'. As Thoreau observed, 'We need to ask whether our inventions are but improved means to an unimproved end'.

DISASTERS OF GOOD INTENT

As the weapons of modern medical warfare increase in effectiveness, there is growing awareness of paradoxical outcomes on the 'battlefield'. One such 'disaster of good intent' followed a very successful campaign to eradicate malaria in Guyana. ${ }^{10}$ Infant mortality was reduced to one third the previous rate, and population almost doubled (from 66000 in 1957 to 110000 in 1966). But technical/ agricultural resources to accommodate the expanded population lagged far behind. Authorities began to question the wisdom of instituting malaria control unless it could be accompanied by effective population control programmes, and by increase in food, clothing, housing, and education. The doubts were heightened by the subsequent experience with the targeted disease. After a period of control, the numbers of mosquitoes increased to the earlier density at a time when the human population's collective immunity fell away. When malaria recurred, it was explosive and exceptionally severe.

During his tenure as Minister of Health in Greece, Spyros Doxiadis recognised that many ethical dilemmas turn up in present day health promotion. Before his death, he wrote movingly about the need to explore such conflicts. ${ }^{11}$

\section{The Doxiadis dilemma}

The problem of deciding how to mount organised efforts to reduce mortality and morbidity in socially disadvantaged, high risk human populations - I would like to call it 'the Doxiadis dilemma' - brings me to the title of the 1994 Windermere Lecture: How do we go about drawing a line between 'knowing' and 'doing' in medicine at the end of the twentieth century? When do we know enough about the full medical and social consequences of our interventions to proceed with confidence?

In the US, a stark example of the dilemma is seen in the contrast between the enormous amount of effort and resources deployed to provide unlimited intensive treatment for marginally viable neonates, and the piddling amounts of social support and money made available to improve the living conditions of overwhelmed families who must care for the fragile survivors. In too many instances, the pregnancies were not planned, the children were not wanted, and a disproportionate number of the distressed families are socially disadvantaged. A disturbing number of prematurely born infants are born to the poor, to the unemployed, to welfare recipients, to undereducated school leavers, to the medically underserved, and to teenage mothers (them- selves frequently unloved children in dysfunctional families). The brittle families are poorly fed and inadequately housed in the midst of drug ridden, violent neighbourhoods. The stress of daily survival is endlessly corrosive.

\section{SHIFT IN ATTITUDES AND ACTION}

Unlike the past, when rescue efforts were ineffective, and the parents' wishes to withhold even simple supportive care for a marginally viable infant were almost always respected, the present situation is unprecedented in all of human history. With the sharp increase in medical knowledge and in development of highly effective interventions, there has been a remarkable shift in attitude and in medical action. The results have been dramatic, as measured by the survival of infants who were abandoned only a short time ago as 'previable' or 'hopelessly malformed'.

The full social costs of this extremely expensive, aggressive, high tech war on neonatal mortality have, for the most part, not been measured. The situation reminds me of the bitter lyrics of an old antiwar song, ${ }^{12}$ "“Once the rockets are up, who cares where they come down?/That's not my department," says Wernher von Braun'.

A growing number of voices are asking about the effects on families and on the community at large. They question the advisability of making technical intensive efforts to prolong the lives of all infants with complete disregard of the far reaching social consequences. The myopic outlook of never say die neonatal warfare reminds me of the attitudes in the disastrous war in Vietnam. One of our officers justified the torching of all straw huts in a settlement with the explanation, 'We had to destroy the village to save it'.

\section{Medical decisions in pluralistic societies}

The decisions about how far we can, or must, go in the deployment of high powered medical weaponry - the line between knowing and doing in medicine - should not, in my opinion, be made by specialists. Medical warfare is not all that different from conventional war ('the continuation of politics by other means'13); it is much too important to be left to the experts. (Note that the medical movement to rescue feeble neonates was motivated by considerations of conventional war. The campaign began in France after the enormous loss of life in the Franco-Prussian War of 1870-1, and it was driven by the need for an increased number of soldiers to fight Germany again. ${ }^{14}$ )

Freidson examined the limits of professional knowledge from a sociologist's point of view. ${ }^{1}$ He concluded that when decisions are essentially 'moral or evaluative, rather than substantive, layman have as much, if not more to contribute than experts'. This assumption, he argued, 'reflects the property of equality in a free society: equality, not of ability, not of knowledge, nor of means; but that of moral equality'. A legal scholar recently came to a similar conclusion: Dworkin has written that 
'The most important feature of Western political culture is a belief in individual human dignity. People have the moral right, and the moral responsibility', he continued, 'to confront the most fundamental questions about the meaning and value of their own lives for themselves' ${ }^{15}$

\section{A COLLISION OF TWO FORCES}

As we approach the twenty first century, on the threshold of the genetics revolution, the increasing technical power of modern medicine is, I suggest, on a collision course with an equally significant revolution in the composition of modern societies brought on by massive migrations. Societies are becoming explicitly and stridently pluralistic.

Medicine's monistic view of what constitutes a good life clashes, inevitably, with the innumerable and kaleidoscopic views of the multiethnic populations in many countries of the Western world. A bioethicist has pointed out that medicine has emerged as a secular profession treating individuals drawn from many cultural and religious backgrounds. ${ }^{16}$ As a result, he argued, it must adopt a neutral stance as it attempts to respond to the expressed needs of a wide variety of religious believers and non-believers; whites, blacks, browns, and yellows; homosexuals and heterosexuals; the able and the disabled ...; the numbers of subcategories that are proclaiming the right of self determination are growing. In choosing among different possible modes of medical treatment, or in rejecting all specific treatment, the cultural subgroups, families and individuals are demanding the right to choose their own sickness styles and their own death styles; to write, in essence, their own life stories. ${ }^{17}$

\section{QUO VADIMUS?}

The collision between medicine and the emerging heterogeneous societies need not be a disastrous encounter. In fact, I see this as an opportunity for a newly powerful medicine to step back and examine itself: Where are we going?

Almost two decades ago, the director general of the World Health Organisation recognised the importance of examining the objectives of modern aggressive medicine. 'It is clear to me', he said, 'that every society needs a redefinition of its health goals'. ${ }^{18}$ It is encouraging to see that his call has, at last, been heeded: an international project has now been launched to examine the ends of modernmedicine. Under the auspices of The Hastings Center in the US, leaders from 10 countries around the world are discussing a series of questions that begins with the general query, 'What ought to be the goals and ends of medicine in the coming decades?' (D Callahan, E Parens. The goals of medicine project. New York: The Hasting Center, in preparation.) This is a daunting undertaking, but it could not be more timely. There is, I think, widespread concern that the unrestrained application of medicine's enormous technical power is making it dangerously fanatical. (Fanaticism, Santayana once observed, consists of redoubling your efforts, after forgetting your aims.)

The Windermere lecture was given at the Annual Meeting of the British Paediatric Association on 14 April 1994, University of Warwick.

1 Freidson E. Profession of medicine. A study of the sociology of applied knowledge. New York: Dodd, Mead, 1970.

2 Asher R. Richard Asher talking sense. Tunbridge Wells: Asher R. Richard Asher talking sense
Pitman Medical Publications, 1972.

Pitman Medical Publications, 1972.
Parsons T. The social system. Glencoe: Free Press, 1951.

3 Parsons T. The social system. Glencoe: Free Press, 1951.
4 Silverman WA. Retrolental fibroplasia: a modern parable. New York: Grune and Stratton, 1980

5 Callahan D. What kind of life? The limits of medical progress. New York: Simon and Schuster, 1990.

6 Callahan D. Setting limits. Medical goals in an aging society. New York: Simon and Schuster, 1987.

7 Lewis J. The humanitarian theory of punishment. Res fudicatae (Australia) 1952; 6: 224-8.

8 Rothman DJ. Introduction. In: Gaylin W, Glasser I, Marcus S, Rothman DJ, eds. Doing good. The limits of benevolence. Sew York: Pantheon Books, 1978.

9 Postman N. Technopoly. The surrender of culture to technology. New York: Alfred A Knopf, 1992.

10 Desowitz RS. New Guinea tapeworms and fewish grandmothers: tales of parasites and people. New York: WW Norton, 1981.

11 Doxiadis S. Introduction. In: Doxiadis S, ed. Ethical dilemmas in health promotion. Chichester: John Wiley, 1987.

12 Lehrer T. That was the year that was. New York: Reprise Records. No 6179, 1965

13 von Clausewitz K. On war. [English translation.] Princeton: Princeton University Press, 1957.

14 Cone TE Jr. History of the care and feeding of the premature infant. Boston: Little, Brown, 1985.

15 Dworkin R. Life's dominion. New York: Alfred A Knopf, 1993.

16 Engelhardt HT Jr. Bioethics in pluralist societies. Perspect Biol Med 1982; 26: 64-78.

17 Brody H. The healer's power. New Haven: Yale University Press, 1992.

18 Mahler $\mathrm{H}$. The quality of life. WHO Chronicle 1976; 30: 259-63. 